\title{
ASSESSMENT OF COLLABORATIVE DESIGN: A SOCIOCULTURAL APPROACH
}

\author{
Virginie TESSIER and Mithra ZAHEDI \\ University of Montreal
}

\begin{abstract}
Designers collaborate with other experts during their projects in order to combine efforts towards greater solutions by creating bridges between disciplinary knowledge. Hence, design teaching establishments introduced team projects in their curriculum. Still, notable gaps persist between the intention and the implantation of assessment activities, which risks reducing the pedagogical value of the learning outcomes. By questioning the assessment of the object emerging from a collaborative design activity, the paper proposes a coherently aligned assessment strategy. Sociocultural assessment perspectives are used as a framework to view learning as a dynamic process mediated through social interactions, contradictions and culminating in knowledge externalisation. This paper offers a structure for an assessment strategy to enhance the practice and learning of collaboration through the development of the reflective skills of design students. The strategy links three main aspects of collaborative design -knowledge creation and integration, communication, and shared understanding- to sociocultural concepts to allow a discussion space for the re-socialisation of collaborative assessment.
\end{abstract}

Keywords: Assessment, collaborative design, design education, activity theory

\section{INTRODUCTION}

Questioning the pedagogical strategies that support the sharing of knowledge and experiences is an important topic as creative solutions to open-ended problems often requires collaboration between experts [1]. Boud \& Falchikov [2] argued, a decade ago, that educational establishments are facing a point where they need to foster autonomous learners to respond to society's changing requirements. Increasing interest on assessment practices and their benefits on learning have led teaching-practitioners and researchers to reflect more deeply on how and why they assess. Although assessment seems to have been an unpopular topic for students, teachers and researchers, influential movements from the past decades have greatly enhanced our knowledge on the subject (i.e. "Formative Assessment", "UK Assessment Reform Group", "Assessment is for Learning" and "Sustainable Assessment") $[3,4,5]$. These movements promote approaches to gain positive impact on student learning: they endorse a multiplicity of assessment functions over exclusive traditional grade certification [6]. Morrissette [7] states that assessment purposes are "re-socialised", meaning they are negotiated in the sociocultural context of the classroom (including the assessor's relation with the students). This article will argue that engaging assessment practices can support the development of metacognitive and reflective skills in design students to strengthen on the field learning of collaboration. By using a sociocultural framework, the authors propose a potential assessment strategy making use of activity theory [AT] concepts and components, which will soon be tested in the field. The main challenge discussed in this article is the integration and assessment of collaboration as part of an existing project-based design learning setting. Design agencies have already adopted interdisciplinary collaboration work methods to produce more creative and sustainable solutions through a process that is acknowledged as more critical. Asking for the expertise of various disciplines and the experience of multiple individuals, design projects are complex systems. Similarly, to Bucciarelli's statement that no one can have an "all-encompassing understanding of the design" [8, p. 298], Klein et al. argue that "the sheer complexity of many design artefacts means that eventually no one person is capable of keeping the whole design in his/her head and assessing/refining its global utility" [9, p. 162]. Moreover, successful collaboration can shorten product development, limit production time, offer solutions more adapted to users and context and enriches individual repertoires [10]. On the other hand, regressive collaboration can lead to invaluable results, 
poor design solutions, longer project schedules, and the adoption of wrong, false or erroneous information [11]. Therefore, our guiding question is: in pedagogical contexts, how should we assess the 'object' emerging from a collaborative design activity? The paper seeks to propose a way to resolve the gaps associated with the assessment of collaborative design projects through the use of a sociocultural framework guiding the components of an assessment strategy to support learning of collaboration. To our knowledge, the framework still carries unexplored avenues regarding the coherent assessment of collaborative design.

\section{COLLABORATIVE DESIGN}

Collaborative design is a form of teamwork with unique interpersonal dynamics. More than just teamwork, collaboration asks for sustained interactions to stimulate 'meaningfully' the experts engaged in the design activity [12]. Through "joint problem solving" [13, p. 410], successfully collaborating teams acquire task interdependence, share knowledge, and develop intersubjectivity [11, 14]. Due to close and efficient interactions, harmony and trust grow to be very important in a team [15]. Scholars have listed characteristics of collaborative design: communication, synchronicity, coordination, reflectivity [15], knowledge creation and integration, communication and shared understanding about content and process [10]. Collaborative design, whether it occurs in disciplinary, interdisciplinary or transdisciplinary contexts, asks for information sharing, risk taking and consensus-building on process and goals to achieve results greater than one would have accomplished alone [13]. As an educational outcome, researchers have demonstrated that collaboration enhances and deepens the quality of learning $[11,16]$. A major aspect of collaboration sits on knowledge sharing and results in situated knowledge creation. Therefore, collaboration emerges from and results in knowledge co-construction according to the project's contextual components. Collaboration contributes to the development of interpersonal skills such as "social, communication and problem-solving skills" [11, p. 105]. It has proven crucial that students trained in collaborative design projects are better prepared for the profession as this approach is now a common practice for companies seeking innovative solutions $[3,16,17,18]$.

\section{ASSESSMENT GAPS}

In response to evolving professional practices, educators have introduced collaboration to project-based pedagogy and have acknowledged its strength to prepare for the profession [3,11, 12]. Still, authors conclude that efforts are needed to ensure its optimal unfolding [7, 16]. Assumptions are made that collaboration is learned from experience, yet Kleinsmann [18] proposes to investigate how this learning process can be enriched through a framed learning sequence. McDonnell adds that "experiences need to be surrounded by apparatus so that learning can ensue, and reflection can take place" [19, p. 155]. A critically important challenge to the comprehensive integration of collaborative design in learning situations resides in the coherence of its assessment. Assessment is now understood as having a powerful impact on the quality of learning since it communicates what is considered crucial to master [2]. Two main gaps are identified between the pedagogical intention and implantation of collaboration: (a) the pedagogical paradigms and (b) the object of assessment. First of all, a gap is noted between the conditions of social learning and individual assessment [11]. This raises interrogations about the conflicting paradigms guiding traditional assessment and contemporary social learning. Traditional assessment favours certification grading, individual and objective knowledge integration at the end of a learning sequence. Although certification ultimately reaches for social aims, to attest the acquisition of certain skills to others, a social paradigm seeks for social enrichment during the learning process through constructive interactions, dynamic learning and situated knowledge externalisation [20, 21]. As researchers working on the topic, we ought to ensure that all pedagogical activities (learning, teaching and evaluating) adopt coherent values for the sake of learning [2]. Secondly, a gap is also identified when assessing the value of a team's final product over the complexity of the collaborative design process. While design is accepted as a social process [8, 10,14], the assessment of a single stage at the end of a project seems puzzling. Similarly, as Chiocchio et al. [15, p. 87] states, "most scholars note the importance of assessing how teams develop over time, but, in the same breath, note the difficulties of conducting studies that can shed light on such processes." 


\section{SOCIOCULTURAL THEORY}

We propose a sociocultural perspective on assessment that will allow a longitudinal strategy to foster learning of collaboration. Regarding learning, the sociocultural perspective places the externalisation of knowledge before its integration by the learner. Emerging knowledge is characterised as situated since it is constantly influenced by the sociocultural context related to the learning activity (team members, classroom, institution, etc.) [7]. Mediation complexifies relations by adding an intermediate component in the interaction. Under the realm of the sociocultural approach, AT proposes a theoretical framework to understand complex situations systemically. AT is based on a triangular seven-component model. As shown in Figure 1, the relation between a subject and its object is mediated by the use of tools, while subject and community are mediated by the rules, and so on. The interrelations between these components lead to the outcome of the activity (in our case collaborative learning as a result of reflective assessment actions). Using a dynamic process, AT favours the active participation of actors in reaching the resolution of persisting systemic contradictions. Contradictions are tensions or controversies that emerge or persist in an activity system. Using an AT mindset, they are seen as occasions for growth, advancement and progress occurring in-between any components of the system [22]. The triangular model seeks to touch all aspects related to a complex process by highlighting the components involved in an activity such as the subject, its object and mediating tools with consideration to social mediators such as rules, community and division of labour. Rogoff [20] states that the sociocultural perspective questions how subjectivity and participation influence the involvement in an activity. Accordingly, the collective zone of proximal development (ZPD) refers to the zone where collaborative initiatives are aligned strategically for the benefit of the project among all actors [22]. Specifically, collaborative behaviours are known to encourage (a) knowledge creation, (b) communication and (c) shared understanding [10]. The authors proposed, in a related book chapter [23], a possible parallel between these skills and foundational AT concepts: (a) mediation, (b) contradictions, and (c) zone of proximal development. The remains of this paper explain the relations between the pairings of these theoretical concepts, the proposed assessment strategy and the associated pedagogical objectives.

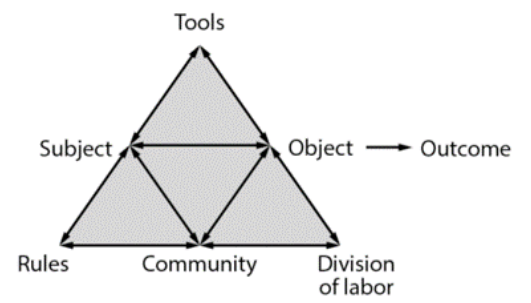

Figure 1. Activity Theory model

\section{PROPOSED ASSESSMENT STRATEGY OF COLLABORATIVE DESIGN}

It is important to note that the assessment strategy proposed in this article is designed to be used consistently by the students to enhance their knowledge of collaboration in addition to the project's specific assessment tasks. Therefore, the authors presume that unclear questions, excessive time-ontask, or difficult access could hinder student participation. Moreover, the assessment strategy is intended to be adapted to a studio setting in order to be implemented by other teachers in the future. As a result, a three-question questionnaire is designed with direct associations to our theoretical framework. Also, the three theoretical pairings are linked with Shepard's main dynamic assessment guidelines [24]. The assessment strategy is built from a longitudinal introspective formative component asking for weekly engagement and a summative group negotiation occurring at the end of the project.

\subsection{Formative assessment}

The formative component of the strategy asks learners to adopt a reflective look at their work. Formative assessment interventions offer opportunities to improve learning through explicit student support, constructive feedback and realignment of teaching initiatives $[4,21]$. Therefore, the intention behind the formative process is to provide a dynamic depiction of a team's evolution through the perspectives of its members. This formative component is accessed through an online questionnaire, which answering should take more or less 20 minutes weekly. The questionnaire is composed of three medium-length development questions ( 7 to 12 lines) framed around the three concept pairings for the sociocultural assessment of collaborative design: (a) ZPD and shared understanding, (b) contradictions and 
communication and (c) mediation and knowledge creation. Students are invited to answer individually each question in relation to their team's recent progress. They are also invited to propose every week assessment criteria regarding their collaboration. These will eventually be grouped in a document for the final summative assessment. Overall, by accessing weekly reports on various aspects of the project, the assessor can initiate a judgement on the evolution of the collaborative dynamics and offer specific coaching to the teams or their members. A discussion space can emerge between the actors of the assessment activity through the valorisation of collaboration. The teacher/assessor can guide, criticise or propose alternative behaviours according to the answers and criteria proposed by the learners.

While all three questions seek to gain insight on individual perspectives, the first question takes a deep dive into the overall project framing -the object of the activity- by asking, 'what is the project?' Over the weeks, the answers translate the project's evolution and the refinement of individual visions. Inspired from Kleinsmann's [10] Ph.D. case study interviews, this question highlights that "viewpoints on [the project] are closely related to their tasks." Centred on shared understanding, the intention behind this first question is to bridge from individual actions/operations to the collaborative activity within the collective ZPD. By comparing the similarities or dissimilarities of individual answers, the assessor can attest qualitatively if a common outcome and process is integrated by the participants or if they are individualised. Such details give insights on the level of collaboration that is occurring and on the coconstruction process emerging from the team's interactions. Co-construction stands for the simultaneous development of a project's outcome and process through the active input of participating individuals. The second question covers in more detail a team's contradictions between any of the AT components by asking, 'how to solve your team's challenges?' Again, by comparing team members' viewpoints, it is possible to indicate if the challenges are isolated or collective. The question allows to confront the students to their challenges and asks them to take a few moments to reflect on their resolution. Too many challenges risk indicating a confusion or disagreement within the team, preventing the emergence of interdependency. Furthermore, answering this question could encourage students to be proactive in proposing possible solutions to plan the next steps and to practice their ability to offer constructive feedback on their team's actions [24]. Evolution in the team's challenges is a sign that the team is moving; to the contrary, redundancy translates that the team is stuck at a certain stage. The final question is concerned with the decision-making process by asking, 'how were recent decisions taken?' Mediation multiplies the opportunities for a team through the many factors and conditions that can modulate the outcome and project's development. Mediators influence the creation of situated knowledge. Framing can translate how parts of a project are linked together toward "goal-directed behaviour and shared rationality in a design team" [18, p. 487]. Here, students make visible the relations in a project by externalising their individual or collaborative cognition [24]. The complexity of the reported cognitive relations ultimately represents the depth of the project's situated knowledge.

\subsection{Summative assessment}

The summative component of the strategy occurs as a team debrief at the end of the project. Inspired from Finland's activity theory Change Laboratory methods (as implemented in CRADLE), this assessment session in intended to provide an opportunity to discuss collectively on the learners' collaborative performance. Also, this debriefing provides a context to discuss an official grading which all team members agree upon. Providing that the teams are encouraged to adopt a reflective approach in relation to their collaboration, a final discussion can provide guidance to improve their future practices. This activity should last around an hour in order for the teams to cover all aspects of their collaboration. In order to orient team's discussions, the AT model is used to provide a systemic view of the detailed components of the design process. The model is presented to the teams with descriptions of each component in a file also including the team's individual anonymised reflective answers to Question 1, organised weekly. The document ends with two open questions related to the team's specific process regarding their challenges and decision process. Answers to Questions 2 and 3 are not exposed publicly to avoid raising conflicts at the end of the project as they may contain more discordant opinions. Using the AT model, learners are asked to model their present practice individually before sharing it with their team. Then, teams share and create a common model of their current practice and identify the main components involved as mediators of their group's decisions and contradictions. Also, to encourage them to progress in the collective ZPD, they propose further development for the improvement of their future collaborative practice. The model supports the externalisation of each team's predominant dynamics. This opportunity to discuss and reflect as a team on the collaborative process offers valuable 
time to socialise as a community of practice [24]. In the meantime, the teacher acts as mediator by stimulating or reorienting dialogues. He or she can use the AT model to interpret the point a team is discussing or to draw attention on a tension. Persistent misunderstandings are likely to emerge during the debriefing and can translate deficient communication or raise questions to stimulate further discussions. When discussion is over, leaners negotiate their assessment criteria among all those they proposed throughout the weeks and grade as a team their collaborative performance.

\section{DISCUSSION AND CONCLUSION}

Inspired from the contemporary perceptions of assessment (i.e. formative assessment and assessment for learning), the assessment strategy proposed serves as an orientation to support the learning of collaboration. In harmony with emergent assessment perspectives, it seeks autonomous learning skills to "foster learning throughout life" [5]. Moreover, formative activities seek to identify strengths and weaknesses on the individual or group level and support the learning process through reflectivity [4]. As Shepard mentions [24, p. 8], "good assessment tasks are interchangeable with good instructional tasks". In the case of our assessment strategy, the formative process is planned to progressively bring the learner to become more curious about the constructive value of collaboration. Lack of coherence between the learning, teaching and assessment activities can mingle the pedagogical objectives and blur its impact on the long-term [2]. Therefore, working in coherence with the sociocultural situated understanding of learning processes, the strategy proposed here aims to actively involve teams in their own assessment process. As design activity endorses social and reflective dynamics, the assessment strategy seeks to recreate as closely as possible such a context. Teams have a direct impact on the coherence of assessment "re-socialisation" due to the emerging distinctiveness of their collaborative dynamics [7]. Mediation of assessment objectives occurs through the re-socialisation of the object being assessed, allowing the emergence of a framed discussion space between team members and between the assessor and the teams. Moreover, AT recognises the benefits of formative interventions through a form of collaboration emerging from a shared object: evolving from collaborative efforts to an expanded object taking place through learning [22, 25]. Formative interventions favour expansive learning, guiding the subject of the activity toward greater and unpredictable outcomes. For educational purposes, formative interventions allow the construction of emerging situated knowledge, the revision of incomplete knowledge, the practice of reflective and critical thinking skills and the enhancement of learning through increased participation. Gipps invites "teachers to bring pupils into the process of assessment, in order to recognise their social and cultural background, and into self-assessment, in order to develop their evaluative and metacognitive skills" [21, p. 387]. Lastly, the proposed assessment strategy seeks in-depth learning by applying small scale Change Laboratory methods and initiating expansive learning. This form of learning can'tbe forced, but "emerges as practitioners struggle through developmental transformations in their activity systems, moving across collective zones of proximal development" [22, p. xvi). In the context of pedagogical design projects seeking to learn collaboration, the assessment strategy strives for deep understanding and profound changes in the collaborative behaviours of the learners. Moreover, the use of such an assessment strategy will hopefully guide toward increased autonomy in learning, assessment and self-assessment skills, and reflective and critical thinking skills.

In conclusion, the strategy proposed in this article is largely based on theoretical explorations since it hasn't yet been implemented. Challenges reside in the longitudinal participation of learners for the strategy to offer regular and rich data. Moreover, the applicability of the strategy still has to be confirmed for large classes of students, which might become too time-consuming for teachers. Next steps consist in the deployment of the strategy as part of a studio-based collaborative design project. The use of the strategy will allow us to gain more knowledge on its repercussions on students' learning of collaboration. Following stages of research may result in changes in the strategy to gain efficiency and coherence according to our observations. In accordance with Shepard [24, p. 10], this paper seeks to revisit the purposes and meanings of assessment so that it becomes "a source of insight and help." Seeking for coherence with the discipline's values and practices is one way to revisit assessment and adopting a sociocultural perspective is another. The theory views learning as a dynamic process mediated through social interactions, enhanced by contradictions and culminating in situated knowledge externalisation stimulating the emergence of a space for the collective re-socialisation of assessment. 


\section{REFERENCES}

[1] Ludvigsen S. and Nerland M. Knowledge Sharing in Professions Working Creatively with Standards in Local Settings. In A. Sannino \& V. Ellis (Ed.), Learning and Collective Creativity: Activity-Theoretical and Sociocultural Studies, 2014, 116-132 (Routledge: New York).

[2] Boud D. and Falchikov N. Rethinking assessment in higher education: Learning for the longer term, 2007 (Routledge: London).

[3] Tucker R. The Impact of assessment modes on collaborative group design projects. In S. Frankland (Ed.), Enhancing Teaching and Learning through Assessment, 2007, 214-222. (Springer: Hong Kong).

[4] Morrissette J. Un panorama de la recherche sur l'évaluation formative des apprentissages. Mesure et Évaluation En Éducation, 2010, 33, 1-27.

[5] Boud D. and Soler R. Sustainable assessment revisited. Assessment \& Evaluation in Higher Education, 2016, 41, 400-413.

[6] Laveault D. and Allal L. (Eds.). Assessment for learning: Meeting the challenges of implementation, 2016 (Springer International Publishing: Cham).

[7] Morrissette J. La portée d'une perspective socioculturelle de l'évaluation formative : Vers l'élargissement d'une conceptualisation. Mesure et évaluation en éducation, 2009, 32(2), 1-27.

[8] Bucciarelli L. Designing and learning: a disjunction in contexts. Design Studies, 2003, 24(3), 295-311.

[9] Klein M., Sayanna H., Faratin P. and Bar-Yam Y. The Dynamics of collaborative design: Insights from complex systems and negotiation research. In Complex Engineered Systems: science meets technology, 2006, 158-174 (Springer Berlin Heidelberg: Berlin).

[10] Kleinsmann M. Understanding collaborative design (Ph.D.). 2006 (Netherlands: Delft University of Technology).

[11] Sainsbury E.J. and Walker R.A. Assessment as a vehicle for learning: Extending collaboration into testing. Assessment \& Evaluation in Higher Education, 2008, 33(2), 103-107.

[12] Achten H. (2002). Requirements for Collaborative Design in Architecture. Presented at Design \& Decision Support Systems in Architecture, 2002, (Netherlands: Avegoor).

[13] Kvan T. Collaborative design: what is it? Automation in Construction, 2000, 9(4), 409-415.

[14] Valkenburg R. Shared understanding as a condition for team design. Automation in Construction, 1998, 7, 111-121.

[15] Chiocchio F., Forgues D., Paradis D. and Iordanova I. Teamwork in Integrated Design Projects: Understanding the Effects of Trust, Conflict, and Collaboration on Performance. Project Management Journal, 2011, 42(6), 78-91.

[16] Webb J. and Miller N. Some preparation required: The journey to successful studio collaboration. Journal of Interior Design, 2006, 31(2), 1-9.

[17] King P.E. and Behnke R.R. Problems associated with evaluating student performance in groups. College Teaching, 2005, 53(2), 57-61.

[18] Kleinsmann M., Deken F., Dong A. and Lauche K. Development of design collaborative skills. Journal of Engineering Design, 2012, 23(7), 485-506.

[19] McDonnell J. Gifts to the future: Design reasoning, design research and critical design practitioners. The Journal of Design, Economics, and Innovation, 2015, 1(2), 107-117.

[20] Rogoff B. Cognition as a collaboration process. In W. Damon (Ed.), Handbook of child psychology: Vol. 2. Cognition, perception, and language, 1998 (John Wiley \& Sons: Hoboken).

[21] Gipps C. Socio-cultural aspects of assessment. Review of research in education, 1999, 24(1), 355-392.

[22] Engeström Y. Learning by expanding: An Activity-theoretical approach to developmental research (2nd ed.), 2015 (Cambridge University Press: New York).

[23] Tessier V. and Zahedi M. Under review. Cadre socioculturel de l'évaluation pour l'apprentissage du design collaboratif. In D. Leduc \& S. Béland (Eds.), Regards surl'évaluation des apprentissages en arts à l'enseignement supérieur.

[24] Shepard L. The role of assessment in a learning culture. Educational Researcher, 2000, 29(7), 414.

[25] Sannino A. and Ellis V. Learning and collective creativity: Activity-theoretical and sociocultural studies, 2014 (Routledge: New York). 